\title{
Design Component and System Reliability in a Low-Rise Cold Formed Steel Framed Commercial Building
}

\author{
B. H. Smith ${ }^{\mathrm{a} 1}$, S. R. Arwade ${ }^{\mathrm{a}}$, B. W. Schafer ${ }^{\mathrm{b}}$, C. D. Moen $^{\mathrm{c}}$ \\ ${ }^{a}$ Dept. of Civil \& Env. Engg., University of Massachusetts, Amherst, MA 01003. \\ SmithBH@Members.ASCE.org, Arwade@UMass.edu. \\ ${ }^{\mathrm{b}}$ Dept. of Civil Engg., Johns Hopkins University, Baltimore, MD 21218. Schafer@ JHU.edu.

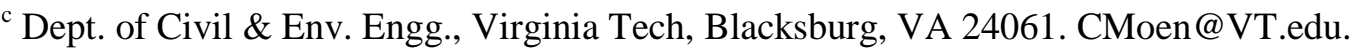

\begin{abstract}
:
Target structural reliabilities are implicit in most modern design codes and yet efficiency of design and construction as well as the presence of constraints on the design space mean that structural components in a building system may have as-designed reliabilities that differ from the target reliabilities. This paper presents an investigation of this phenomenon through a detailed examination of the two story cold-formed steel framed building designed and tested as part of the CFS-NEES project and seeks to use this case study to elucidate features of the component and system reliabilities that may prevail in typically designed buildings. Specifically, for the gravity load system of the second floor and the lateral force resisting system the demand to capacity $(D / C)$ ratios and reliabilities $(\beta)$ are calculated. The results of these calculations illustrate the excess and highly variable $\mathrm{D} / \mathrm{C}$ ratios and reliabilities that result from efficient design procedures. Since the ultimate goal of structural design is to ensure performance of the structural system at a target level of reliability the influence of excess and variable component reliability on reliability of the lateral force resisting system is examined by making assumptions about series and paralleltype interaction of the floor diaphragm and shear walls. Finally, discussion is presented about the role of load combinations and their associated coefficients of variation in determining component and system reliability in a cold-formed steel framed building. Future considerations include more robust, high fidelity, modeling of the system effects and evaluation of excess capacity and variability of reliability across suites of other building designs and structural systems such as roof trusses.
\end{abstract}

KEYWORDS: Structural Reliability, Design Efficiency, Cold-Formed Steel; Probabilistic Design; Steel Design

\section{Introduction}

Modern design approaches for buildings are based on underlying target reliabilities for each of the building's structural components. The target reliability, or probability of failure, varies between element types (e.g. connections are usually designed with a higher target reliability than members), often depending on how critical a particular component is to the performance of the overall building system. In a perfectly optimized structural design each component would be sized such that it exactly meets its target reliability. In practice, however, such fine-grained optimization is neither practical nor desirable for reasons including cost savings generated by consistency of member sizes within the building, commercial availability of members only in

1 Corresponding author: 223 Marston Hall, University of Massachusetts, Amherst, MA 01003. SmithBH@Members.ASCE.org, +1.603.443.1038.

C) 2016. This manuscript version is made available under the Elsevier user license

http://www.elsevier.com/open-access/userlicense/1.0/ 
discrete size and shape increments, and the possibility that a given member is sized according to a serviceability rather than ultimate strength limit state. These factors combine to cause building designs to contain widely varying component reliabilities that may differ significantly from the target reliabilities. This variability of the as-designed reliabilities has implications for the overall structural efficiency of the building as well as for the overall reliability of the structural subsystems and systems such as shear walls, floor diaphragms, and gravity load-bearing walls that form a building. While the existence of these effects are known, especially relative to constructability, they have not, to the authors' knowledge been quantified for a realistically designed building, and a thorough understanding of the extent of excess and variable component and system reliability is required to improve upon reliability-based design practices.

The issues that affect the as-designed reliability are particularly acute for cold formed steel (CFS) structures, for which repetitive framing and a dense network of structural elements is typical, and which contain larger numbers of connections and fasteners than hot-rolled steel or reinforced concrete structures. It should be noted that the term 'as-designed' is used in this paper to describe the predicted reliability of the structural members as specified by the design engineer and that the 'as-built' reliability may differ significantly from the as-designed reliability due to myriad effects including member imperfection, construction misfit, and the influence of non-structural systems, among others.

Component design methodology has existed for cold-formed steel for some time, but it is only in the past 20 years that full-building solutions, notably integrating seismic design, have been developed for CFS. Since an initial characterization of wood sheathed CFS shear walls by Serrette et al [1], research has focused upon experimental studies of shear walls [2], fasteners [3], and prototype buildings [4]. Numerical models [5] and complete seismic design procedures [6] have been developed, and the recent popularity of CFS residential structures in Australia and China have led to growing data on lateral force resisting systems for the material $[7,8]$.

The positive or negative effects of having multiple interconnected structural components acting together is known as the system reliability. While research in system reliability has rarely focused specifically upon CFS, important contributions have included studies of load paths $[9,10]$ as well as of redundancy, load distribution, and uncertainty in demands and capacities [11]. Among other things, this system reliability depends upon the load-deformation characteristics of each component acting together [12].

The CFS-NEES project (part of the larger NEESR-CR project) [13] funded by the US National Science Foundation, presents a unique opportunity to investigate the as-designed component reliabilities of a low-rise CFS building designed according to the latest US design codes. As part of the project a full-scale shake table test of a two-story CFS building was conducted at the NEES@Buffalo site at the University at Buffalo of the State University of New York. The performance of the building during the shake table test indicated that the as-designed (and asbuilt) components, subsystems and systems performed well in excess of design specifications. Specifically, the building was subjected to a full proof test at design gravity load levels and was then subjected to simulated design basis (DBE) and maximum considered (MCE) earthquake excitations with the full gravity load in-place. The building performed well in excess of design expectations at these load levels, exhibiting greater strength and stiffness than anticipated by the design $[14,15]$. While these results clearly indicate that the demand-to-capacity $(D / C)$ ratios of all system components were less than one, there is no viable way to extract component $D / C$ ratios from a full-scale building test. A detailed discussion of the methodology and results from the shake table testing is outside the scope of this paper, and the interested readers are referred to other publications from the CFS-NEES project for such information $[14,15,16]$. The primary importance of the CFS-NEES building to this work is that it provides a thorough, openly available CFS building design that has been proof-tested under design gravity and seismic loads. 
Such performance indicates substantial reserve strength in the components, or significant parallel system or load sharing behavior among components and subsystems that is not accounted for in component-based design. Furthermore, the CFS-NEES building utilizes the repetitive framing typical of CFS constructions and the project therefore provides an opportunity to assess component and system reliabilities for a repetitively framed structure.

This paper presents calculation and discussion of the as-designed demand-to-capacity $(D / C)$ ratios and reliabilities for the structural components of the CFS-NEES building. The $D / C$ ratios are included in the paper because they are more directly connected to the code checks performed during design than are the reliabilities. $D / C$ ratios can be computed based on factored $\left(D_{f} / C_{f}\right)$ or unfactored $\left(D_{u} / C_{u}\right)$ values of the demand and capacity. $D_{f} / C_{f}$ can be easily interpreted relative to the key value of $D_{f} / C_{f}=1$, at which the component exactly meets the design check and therefore would also be expected to exactly meet the target reliability implicit in the code. Unfactored values $D_{u} / C_{u}$ are also included here to indicate the amounts of relative safety margin provided by code factors. There are subtleties in the computation of $D_{u}$ and $C_{u}$ primarily associated with the variety of load combinations that may control a given component design, and in some cases assumptions have been made to allow computation of unfactored quantities. Detailed procedures are presented in the following sections. Once values of $D$ and $C$ are computed, component reliabilities for the factored, $\beta_{f}$, and unfactored, $\beta_{u}$ cases can be computed by making appropriate assumptions about the variances and distributions of $D$ and $C$ or the ratio $D / C$ itself. Some key limitations of the paper are that it treats a single building rather than an ensemble of building archetypes representative of the current building stock, and that it uses approximations for the coupling of the building systems to arrive at overall system reliabilities.

The remainder of this paper is organized as follows: first the general characteristics of the CFSNEES building are reviewed; second, the detailed methods used to compute $D, C$, and the resulting values of $\beta$ are described; third, the results of those calculations are presented, followed immediately by discussion of those results; fifth and finally, preliminary analysis of the effect of component reliabilities on building system reliability is presented. The paper closes with a summary of conclusions.

\section{General characteristics of the CFS-NEES building}

The CFS-NEES building (Figure 1Error! Reference source not found.) was professionally designed by Rob Madsen of Devco Engineering with input from the CFS-NEES research team led by one of the authors (Schafer) and from an Industry Advisory Board comprised of experienced cold-formed steel engineers in the U.S. and Canada. The design was intended to reflect current practice. The building has a rectangular floor plan dimensions of $15.1 \mathrm{~m} \mathrm{x} 6.97 \mathrm{~m}$

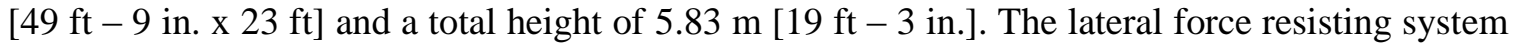

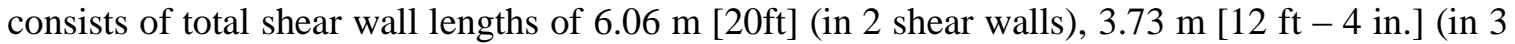

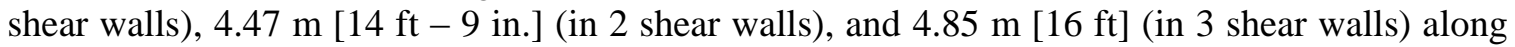
the north, south, east and west sides of the building, respectively.

The second floor acts as a diaphragm to distribute lateral loads to the shear walls. The floor is ledger-framed, i.e., a ledger track is installed on the inside face of the wall studs and the floor joists are attached to this track with clip angles. Stud and joist spacing are not equal in ledgerframing. The top of joist and top of wall are at the same elevation. Oriented strand board (OSB) sheathes the floor and runs through to the outside edge of the walls providing direct diaphragm transfer between the floor and top track of the walls. The building uses OSB sheathed shear walls for the lateral force resisting system, corresponding to a response modification factor $(R)$ of 6.5 per ASCE 7-05 [18]. The building was designed for Orange County, CA (site class D) with a total seismic weight of $350 \mathrm{kN}$ [78 kips]. Resulting shear forces, calculated by the Equivalent Lateral 
Force method [18], are $20 \mathrm{kN}$ [4.5 kips] for the second floor and $29 \mathrm{kN}$ [6.5 kips] for the roof. A design narrative, complete calculations, and full drawings are available for the building [13,17].

In this paper, a total of 131 component design checks are examined in detail. These relate to the second floor gravity system and the sets of shear walls along each side of the building. Table 1 defines the component groups with the corresponding number of components in each group. The design check on the shear walls acts as both a check on the capacity of the sheathing boards and on the system capacity of the shear wall itself since the check involves the fastener type and spacing and the chord stud size (AISI S213-07). In the following the shear wall check is treated primarily as a component check and labeled as a check on the 'sheathing component'. In the discussion section its role as a shear wall system capacity check is discussed. Gravity studs are not discussed in this paper since they have been designed based on a single critical component, similar to the joists, and therefore features of the component $D / C$ ratios and reliabilities are similar to those for the joists.
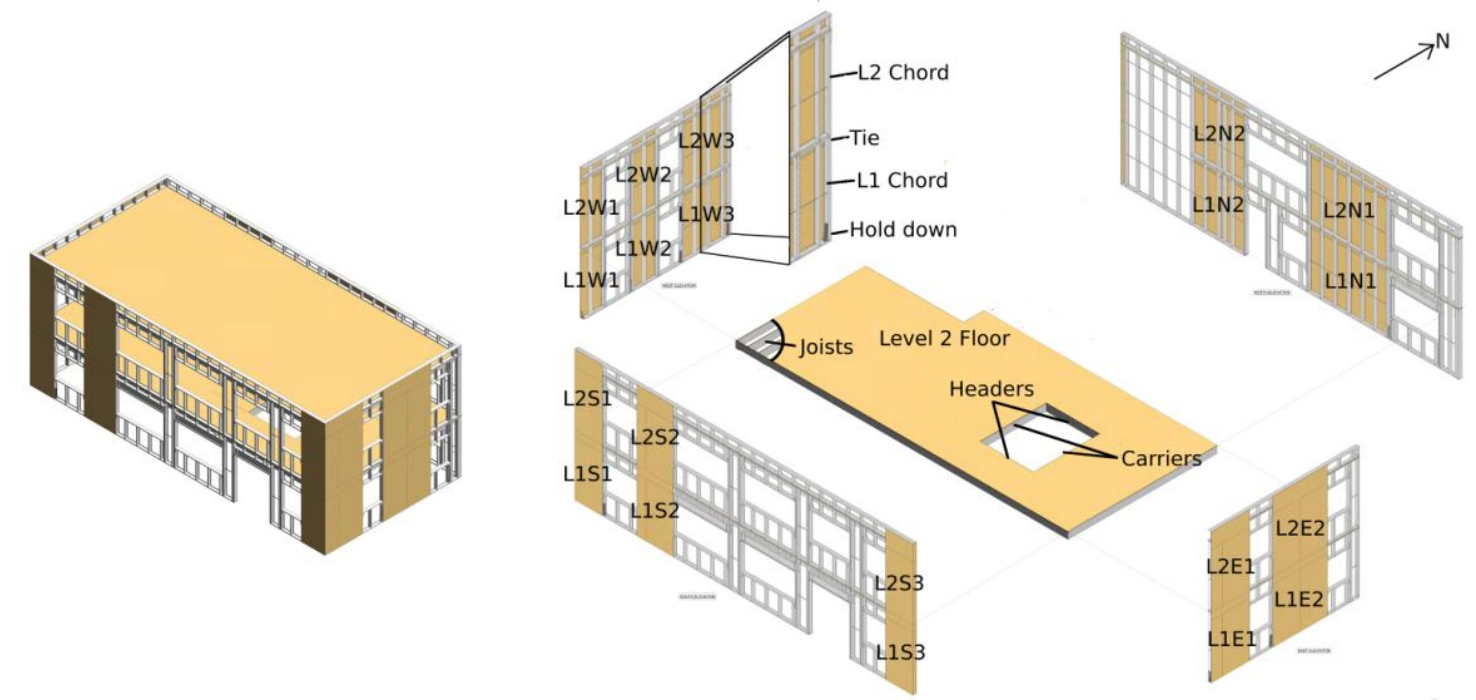

Figure 1: CFS-NEES building components and subsystems, showing isometric assembled (left) and exploded (right) views, with labels as used in this paper. Sheathing is depicted on shear walls and the diaphragm only, noted as Phase 1 in [13]) 
Table 1: Groupings and counts for CFS-NEES building components studied in this paper.

\begin{tabular}{|c|c|c|}
\hline System & Group & $\begin{array}{l}\text { Number of } \\
\text { components }\end{array}$ \\
\hline \multirow[t]{3}{*}{$2^{\text {nd }}$ floor gravity } & All components & 31 \\
\hline & Joists & 27 \\
\hline & Headers/Carriers & 4 \\
\hline \multirow[t]{5}{*}{ North shear wall } & All components & 20 \\
\hline & Ties & 4 \\
\hline & Hold downs & 4 \\
\hline & Sheathing & 4 \\
\hline & Chord studs & 8 \\
\hline \multirow[t]{5}{*}{ South shear wall } & All components & 30 \\
\hline & Ties & 6 \\
\hline & Hold downs & 6 \\
\hline & Sheathing & 6 \\
\hline & Chord studs & 12 \\
\hline \multirow[t]{5}{*}{ East shear wall } & All components & 20 \\
\hline & Ties & 4 \\
\hline & Hold downs & 4 \\
\hline & Sheathing & 4 \\
\hline & Chord studs & 8 \\
\hline \multirow[t]{5}{*}{ West shear wall } & All components & 30 \\
\hline & Ties & 6 \\
\hline & Hold downs & 6 \\
\hline & Sheathing & 6 \\
\hline & Chord studs & 12 \\
\hline \multirow[t]{5}{*}{ All shear walls } & All components & 100 \\
\hline & Ties & 20 \\
\hline & Hold downs & 20 \\
\hline & Sheathing & 20 \\
\hline & Chord studs & 40 \\
\hline
\end{tabular}

\section{Demand, capacity, and reliability calculation methods}

Through the CFS-NEES project [13] the authors were provided access to design calculations prepared by the consulting engineer charged with design of the CFS-NEES building. These calculations emerge from a typical and efficient design process in which engineering judgment and experience is used to identify critical components within a grouping (e.g. the longest and most heavily loaded second floor joist) and document the detailed design calculations for that member. Other members of the component group can be sized based on that critical member calculation. The more detailed information required for this study, detailed demand and capacity calculations for every component listed in Table 1, is not usually included in a set of design calculations because such detail is not needed when critical members of a component group can be identified. Therefore, additional calculation is performed to obtain values of $D$ and $C$ for all members from which values of $\beta$ can be calculated. These supplementary calculations follow the same procedures as used in original design of the building. Original design calculations 
correspond to ASCE 7-05 [18] for D, AISI S213-07 [19] for parts of the shear wall $C$, and AISI S100-07 [20] for all other $C$; calculations for this study correspond to ASCE 7-10 [21] for $D$, AISI S213-07 [19] for parts of the shear wall $C$, and AISI S100-12 [22] for all other $C$. All demands $(D)$ and capacities $(C)$ are based upon values and methodologies from the standards cited above, calculated in the same manner as a typical building design, but for each individual component within the structure rather than only the critical components.

\subsection{Demand and capacity calculation methods}

In keeping with current practice in the cold-formed steel construction industry, gravity load combinations are based upon Allowable Strength Design (ASD) while lateral load combinations are based upon Load and Resistance Factor Design (LRFD). In AISI S100 nominal capacities are identical for ASD and LRFD and ASD safety factors are tied to LRFD resistance factors based on a single load combination [20,22]. Lateral loads are determined using the Equivalent Lateral Force method for seismic loading (ASCE 7-10 section 12.8); all other lateral forces are significantly smaller than seismic forces and do not govern component design. Specifically, wind loads are neglected in the design of the lateral force system.

Joist components (1200S250-97) in the $2^{\text {nd }}$ floor gravity system (See Error! Reference source not found. for structural layout) are checked for flexure, distortional buckling, combined bending and web crippling, shear, and combined bending and shear. Shear wall system capacity checks include: axial-flexural capacity of the chords; yield, fracture and buckling of the ties that provide continuity between the first and second level shear walls; shear fracture of the fastener screws; yield, fracture, and fastener failure at the hold downs; in-plane shear failure of the OSB; OSBchord fastener pullout and fracture. Unlike the joists; however, many of these failure modes are considered in combination in empirically calibrated design equations, meaning that explicit individual checks for each of the failure modes are not conducted. Shear wall capacity checks also include the seismic overstrength factor, treated here as an additional load factor. The shear wall capacities of Table AISI S213-07 C2.1-3 are treated as sheathing component checks for the purpose of computing system reliabilities.

All design calculations include safety factors (ASD, used for gravity system components) or load and resistance factors (LRFD, used for lateral system components). Thus, the final design calculations provide $D_{f}$ and $C_{f}$, the factored demand and capacity. Additional calculation is required to obtain $D_{u}$ and $C_{u}$, the unfactored demand and capacity of components. Those calculations fall into one of seven categories, based upon the critical limit state. The critical limit state is assumed to be the same as the factored limit state, though $D_{u}$ is taken as the most critical ASD load combination and all combinations are checked. Example calculation methods follow several of the more involved cases.

1. Gravity system (ASD), deflection serviceability limit state: For components governed by deflection limits, a serviceability limit state, rather than an ultimate strength limit state. For this case, $C_{u}=C_{f}$.

2. Gravity system (ASD), single load effect limit state: Where the failure mode involves a stress resulting from a single, isolated, load effect (e.g. flexure), $C_{u}=\Omega^{*} C_{f}$, where $\Omega$ is the ASD factor of safety.

3. Gravity system (ASD), combined load effect limit state: Where the failure mode involves combined stresses from multiple load effects (e.g. combined bending and web crippling), unfactored demand and capacity cannot be calculated directly. Design standards provide interaction equations representing the combined effect of different load effects (for example, flexure and shear). The upper limit to the inequality (typically 1.0) plays the role of factored capacity $C_{f}$, whereas the interaction value itself is the factored demand. The unfactored 
demand $D_{u}$ is obtained by setting all safety factors $\Omega=1.0$ in the interaction equation, and further assuming $C_{u}=C_{f}$. For example, consider joist strength calculations for a combined bending and shear limit state (AISI S100-12, eq. C3.3.1-1) with interaction equation

$$
\sqrt{\left(\frac{\Omega_{b} M}{M_{n x o}}\right)^{2}+\left(\frac{\Omega_{v} V}{V_{n}}\right)^{2}} \leq 1.0
$$

where $\Omega_{b}, M, M_{n x o}, \Omega_{v}, V$, and $V_{n}$ are respectively the bending safety factor, moment demand, braced moment capacity, shear safety factor, shear demand, and shear capacity. The unfactored demand and capacity are then taken to be

$$
\begin{aligned}
& D_{u}=\sqrt{\left(\frac{1.0 \cdot M}{M_{n x o}}\right)^{2}+\left(\frac{1.0 \cdot V}{V_{n}}\right)^{2}} \\
& C_{u}=1.0
\end{aligned}
$$

4. Lateral system (LRFD), shear wall OSB sheathing: The OSB sheathing, one of two main components of the shear wall, is designed based on a demand coming from a load combination of $1.0 \mathrm{E}$, where $\mathrm{E}$ is the seismic load. Therefore $D_{u}=D_{f}$. The unfactored capacity was calculated by simply dividing the factored capacity by the shear resistance factor of 0.60 .

5. Lateral system (LRFD), overstrength or capacity limit state: For certain shear wall component limit states, ASCE 7 prescribes factored demand $D_{f}$ as the minimum of either the overstrength factor times the unfactored demand, or unfactored shear wall system capacity. Component capacity in these limit states is prescribed by ASCE 7 without resistance factors so $C_{u}=C_{f}$ [21]. The unfactored demand $D_{u}$ is taken as the minimum of either the unfactored demand without the overstrength factor, or the unfactored capacity of the full shear wall system. For example, the factored demand and capacity for the tensile capacity of shear wall ties that provide chord stud continuity between floors is

$$
\begin{aligned}
& D_{f}=\min \left(\Omega_{0} \cdot v_{S W} h_{S W}-\phi_{p} P_{D L}, C_{u, S W}\right) \\
& C_{f}=T_{n}
\end{aligned}
$$

where $v_{S W}, h_{S W}, \phi_{p}, P_{D L}$ and $C_{u, S W}$ are respectively the shear demand on the shear wall, the height of the shear wall, the axial resistance factor, the gravity dead load taken by the chord, and the unfactored maximum load capacity of the shear wall. $T_{n}$ is the unfactored tensile capacity of the tie. The unfactored demand and capacity of the ties are then taken as follows:

$$
D_{u}=\min \left(v_{S W} h_{S W}-P_{D L}, C_{u, S W}\right)
$$

$$
C_{u}=T_{n}
$$

6. Lateral system (LRFD), single load effect limit state: Where the limit state involves only one isolated force (e.g. pure axial compression), $C_{u}=C_{f} / \phi, \phi$ being the LRFD resistance factor.

7. Lateral system (LRFD), combined load effect limit state: Where the limit state involves combined forces (e.g. combined axial and flexure), unfactored demands and capacities are obtained in the same manner as Case 3. 


\subsection{Reliability calculation methods}

Based upon the principles of AISI S100-12 section F1, the probabilities of failure and associated reliability index $\beta$ values for each component are calculated. Unfactored demand $D_{u}$ and capacity $C_{u}$, calculated according to the methods described in the previous section, are used to obtain mean demand $\mu_{D}$ and mean capacity $\mu_{C}$ of each member and associated coefficients of variation (COVs), $V_{D}=\sigma_{D} / \mu_{D}$ and $V_{C}=\sigma_{C} / \mu_{C}$. Component reliabilities are then calculated using bias factors and COVs consistent with AISI S100, and assuming that $\ln \left(C_{u} / D_{u}\right)$ is normally distributed with a failure criterion of $\ln \left(C_{u} / D_{u}\right)<0$, such that $\beta_{u}$ is

$\beta_{u}=\frac{\ln \left(\mu_{C} / \mu_{D}\right)}{\sqrt{V_{C}^{2}+V_{D}^{2}}}$

which, expanded to include all of the COVs involved results in

$\beta_{u}=\frac{\ln \left(\mu_{C} / \mu_{D}\right)}{\sqrt{V_{Q}^{2}+V_{M}^{2}+V_{F}^{2}+C_{P} V_{P}^{2}}}$

in which $V_{Q}$ is the COV of the load effect factor, $V_{M}$ is the COV of the material factor, $V_{F}$ is the $\mathrm{COV}$ of the fabrication factor, $C_{P}$ is a correction to the professional factor, and $V_{P}$ is the COV of the professional factor. These factors are provided in AISI S100-12 table F1. The professional factor correction, $C_{p}$ is intended for use in test-based methods when small sample sizes are used and here $C_{p}=1.0$ is assumed, implying that $V_{p}$ corresponds to a large sample size. Assuming

$\mu_{D}=D_{u}$

$\mu_{C}=C_{u} M_{M} F_{M} P_{M} C_{\varphi}$

where $M_{M}, F_{M}, P_{M}$, and $C_{\phi}$ are the mean value of the material factor, the mean value of the fabrication factor, the mean value of the professional factor, and a calibration coefficient, respectively. Combining all of the above, the resultant reliability equation is

$\beta_{u}=\frac{\ln \left(M_{M} F_{M} P_{M} C_{\varphi} /\left(D_{u} / C_{u}\right)\right)}{\sqrt{V_{Q}^{2}+V_{M}^{2}+V_{F}^{2}+C_{P} V_{P}^{2}}}$.

The COV of the load effect, $V_{Q}$, is assumed to be 0.21 throughout as recommended by AISI S100-12 section F1.1(c). This value is used to be consistent with underlying assumptions of the code and the implications of this assumption are addressed in the discussion section. The COVs of fabrication and material, $V_{F}$ and $V_{m}$, are as defined in AISI S100-12 table F1, and depend upon the type of member or connection in question. For joist and stud members for example, $V_{F}$ equals 0.05 and $V_{m}$ equals 0.10 . The COV of the professional factor $V_{P}$ is intended to be calibrated based upon testing, but a theoretical value of 0.10 is used in these calculations [19].

\section{Demand/capacity ratios}

Following the methods described in Section 3 the factored and unfactored demand-to-capacity ratios $\left(D_{f} / C_{f}, D_{u} / C_{u}\right)$ are calculated for each component listed in Table 1. The results of these calculations are shown on drawings of the CFS-NEES building in Figure 2 and Figure 3.

Some notes on the design of the CFS-NEES building aid in interpretation of these results. First, all second floor joists have the same cross sectional dimensions despite widely varying spans and loads. This single cross section was chosen to meet a deflection serviceability requirement, although the serviceability requirement did not result in a significantly larger member size than 
the strength requirement would have. Second, shear wall chord sizes are identical in the first and second levels although demands on the lateral force system necessarily decrease with elevation in the building. In both of these cases, economy is enhanced during design when fewer calculations are needed, and during construction when site management is eased with fewer member sizes to track, yet material economy is decreased since each member is not individually optimized to its demand level.

In the case of the second floor joists, the controlling members are the joists directly on each side of the framed opening in the second floor plan. These members, with $D_{f} / C_{f}=0.91$, approach most closely the strength limit state, for which $D_{f} / C_{f}=1.0$. Reduced material economy is evident in the overall low values of $D_{f} / C_{f}$, as low as 0.28 for the short span joists interrupted by the framed opening.

In the case of the shear walls, $D_{f} / C_{f}$ decreases dramatically from level 1 to level 2, from values of approximately $D_{u} / C_{u} \cong 0.40-0.60$ at the level 1 to values of $D_{u} / C_{u} \cong 0.15-0.25$ at level 2 . It should be noted that the loss of material efficiency cannot be easily interpreted as $1-D_{f} / C_{f}$ since decreasing the member size, thereby decreasing $C$ and increasing $D / C$, may well result in an alternate failure mode being triggered. In other words, the values of $D / C$ reported here correspond to a particular failure mode for the member and achieving $D_{f} / C_{f}=1.0$ for that particular failure mode may not be possible. Nevertheless, it should be noted that maximum values of $D_{f} / C_{f}$ are above 0.91 for most subsytems, indicating a design which achieves nearly maximum efficiency for critical components.

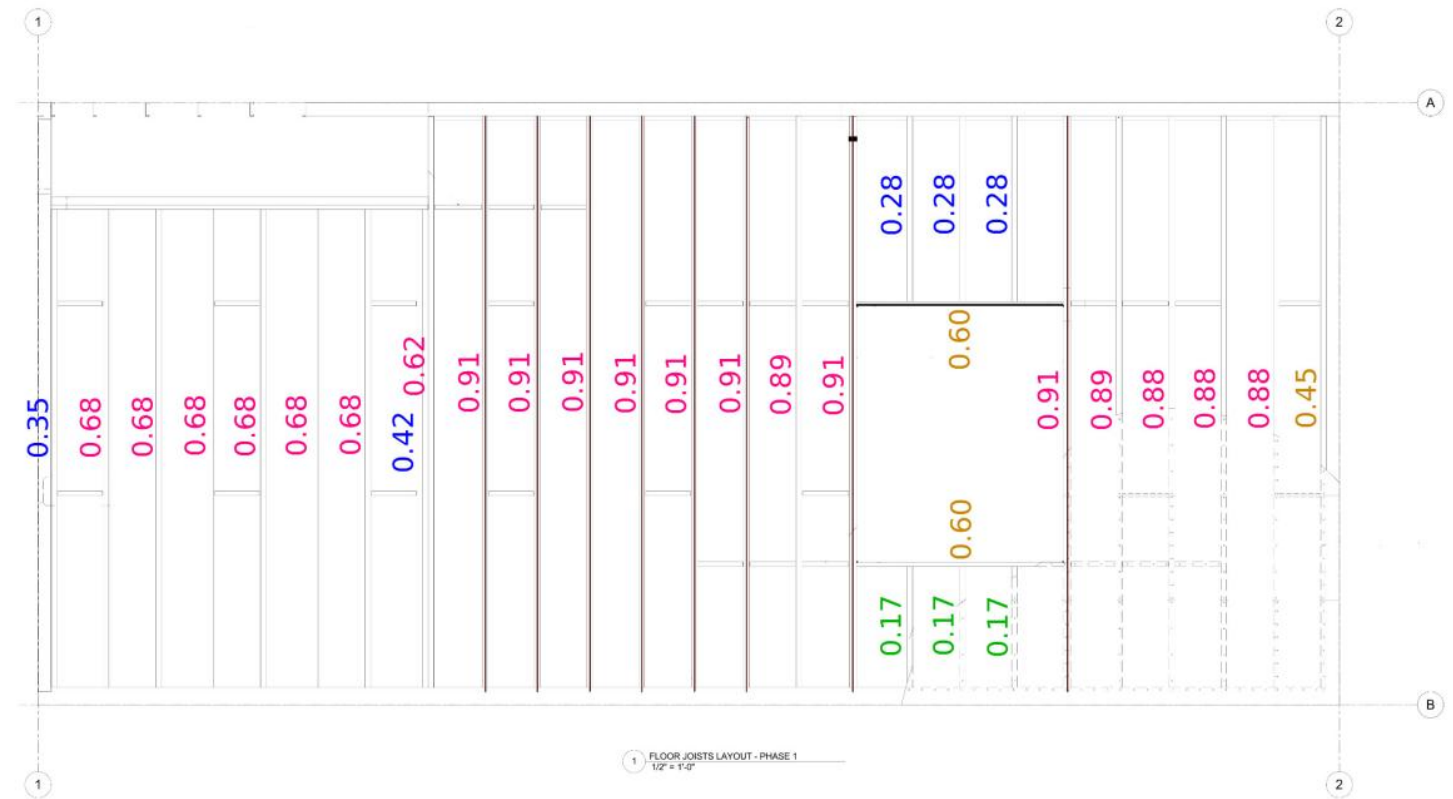

Figure 2: $2^{\text {nd }}$ floor gravity system factored demand-to-capacity ratios $D_{f} / C_{f}$. Text colors correspond to the quartile in which the member lies (see Figure 4), with pink indicating most severe $25 \%$ of ratios, and orange, blue, and green indicating progressively less severe quartiles of $D_{f} / C_{f}$ ratios. Members indicated by a bold black line are the critical members which governed design choices. 


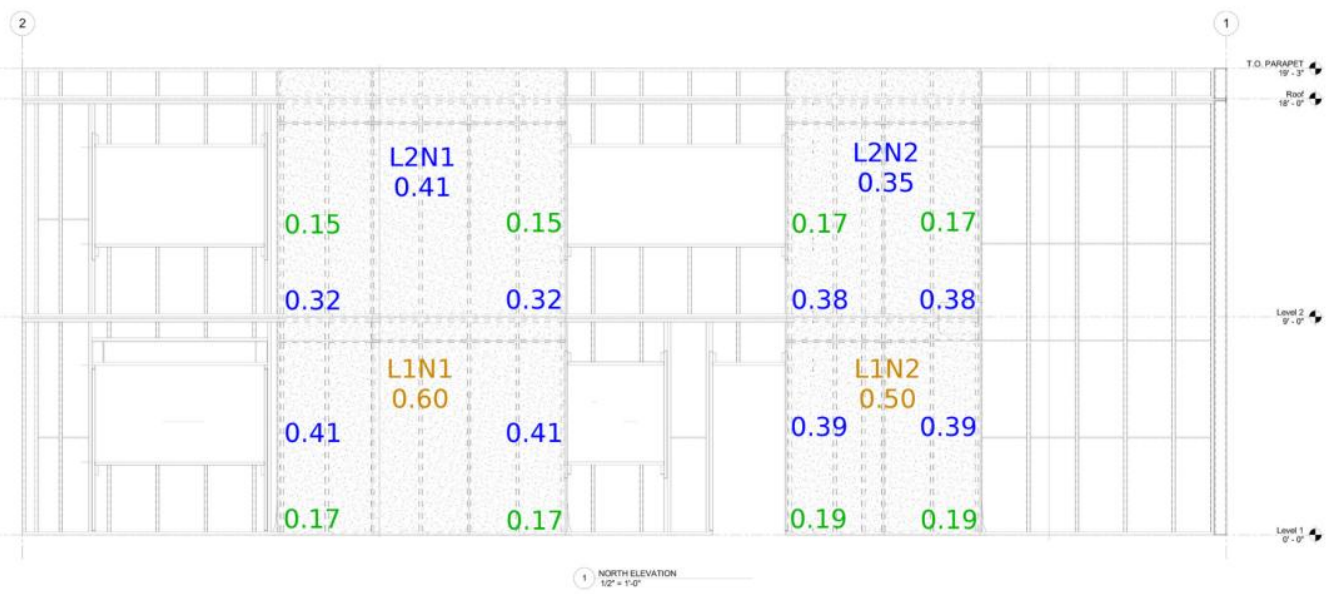

(a) $D_{f} / C_{f}$ for north elevation

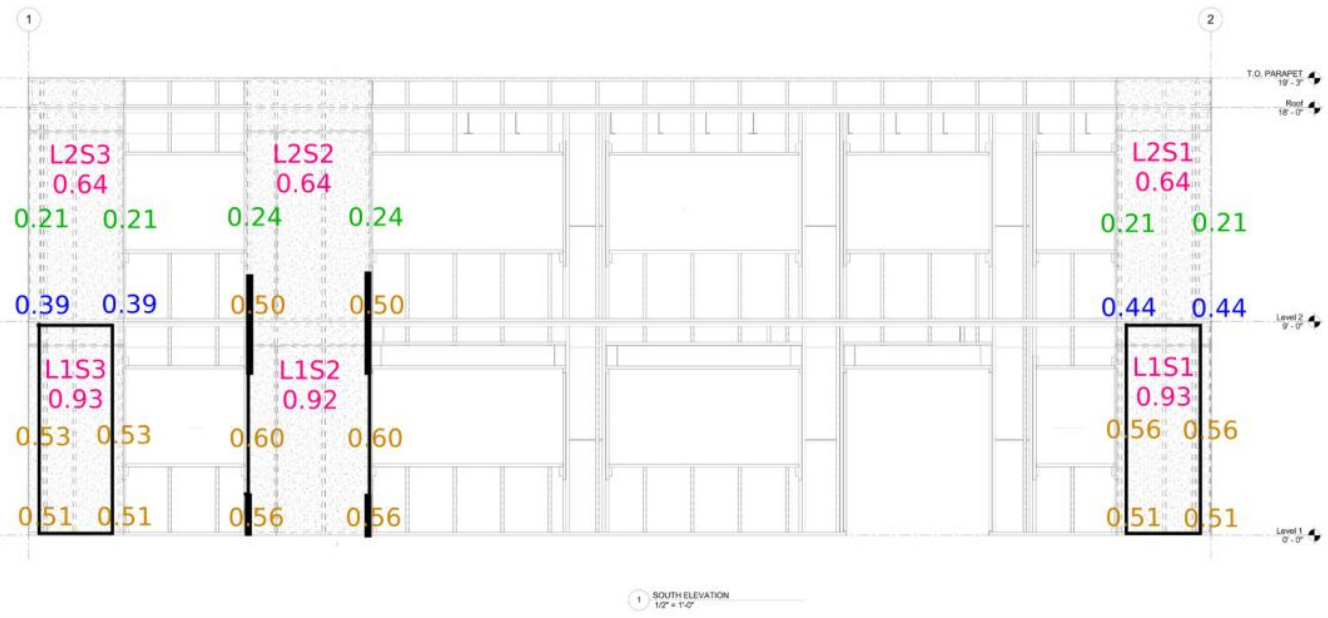

(b) $D_{f} / C_{f}$ for south elevation

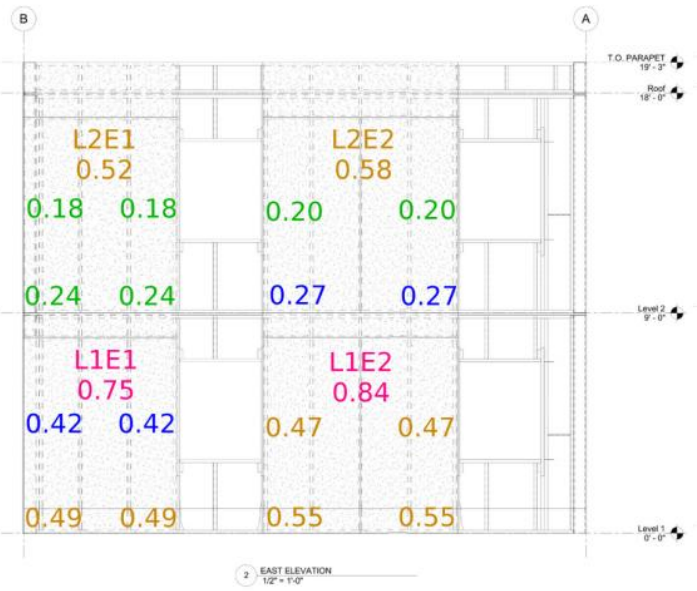

(c) $D_{f} / C_{f}$ for east elevation

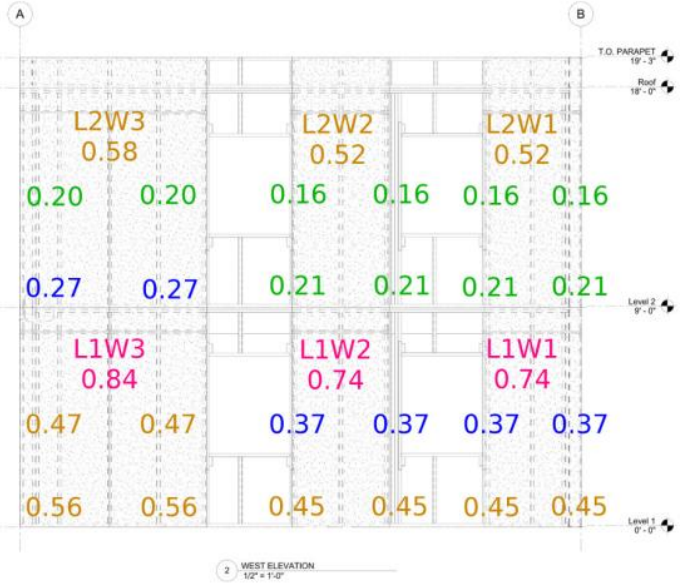

(d) $D_{f} / C_{f}$ for west elevation

Figure 3: Shear wall system factored demand-to-capacity ratios, $D_{f} / C_{f}$. Colors follow the same conventions as in Figure 2. Members indicated by a bold black line or box are the critical members which governed design. 
In a design fully optimized for structural efficiency, $D_{f} / C_{f}=1.0$ should prevail for all members, yet Figure 2 and Figure 3 show that there is a great deal of variability in the as-designed D/C ratios for the CFS-NEES building. Some of the reasons for this variability have been discussed previously, and include the presence of serviceability limit states and the desire for selection of consistent member sizes within a structural system. Such variability should be considered typical of buildings such as the CFS-NEES building since its architectural design is typical and the engineering design was conducted by an experienced practitioner.

A series of $\mathrm{D} / \mathrm{C}$ ratio box and whisker plots (Figures $4-6$ ) are constructed to depict the range of values and to indicate some features of the distribution of the D/C values for the CFS-NEES building. Histograms or distribution fits are not given due to the relatively small number of data points in each component group and the lack of a rationale for choice of a parametric distribution fit. The box and whisker plots provide the following: horizontal black lines at the ends of the vertical dashed lines mark the maximum and minimum $\mathrm{D} / \mathrm{C}$ values within the labeled component group; the top and bottom of the blue box mark the $25^{\text {th }}$ and $75^{\text {th }}$ percentile values; and the red horizontal line within the blue box marks the median value.

Figure 4 provides factored and unfactored D/C ratios for the set of all components in the building. Comparable values (median, maximum, etc) are approximately 1.8 times higher for the factored case, giving a measure of the implicit safety margin/factor present in the design. The median value of $D_{f} / C_{f}$ is 0.45 , indicating a measure of structural inefficiency of 0.55 . While the maximum value $D_{f} / C_{f}=0.91$ approaches the optimal design point of $D_{f} / C_{f}=1.0,75 \%$ of the components in the building have $D_{f} / C_{f}<0.60$ with $25 \%$ of the components having $D_{f} / C_{f}<0.25$. These features, along with the very large range of values of $D_{f} / C_{f}(50 \%$ of components have 0.25 $\left.<D_{f} / C_{f}<0.60\right)$ make clear that typical CFS buildings, as-designed, exceed code requirements by great and greatly varying degrees. Furthermore, the figure demonstrates that for all but the upper tail of the $D / C$ distribution, constructability and design efficiency concerns result in a greater safety margin/factor than do code load and resistance factors (LRFD) or safety factors (ASD). This can be seen in Figure 4 by noting that $1-D_{f} / C_{f}$ reflects excess component capacity resulting from constructability and design efficiencies or serviceability requirements, and that $D_{f} / C_{f}-D_{u} / C_{u}$ reflects the safety margin enforced by the code. For all values shown in the box plot except the maximum, $1-D_{f} / C_{f}>D_{f} / C_{f}-D_{u} / C_{u}$. This result implies that in the as-designed structure more reliability comes from constructability and design efficiencies or serviceability requirements than code-prescribed factors. That this does not hold for the component with maximum $D_{f} / C_{f}$ reflects the high efficiency of critical components achieved in the design. 


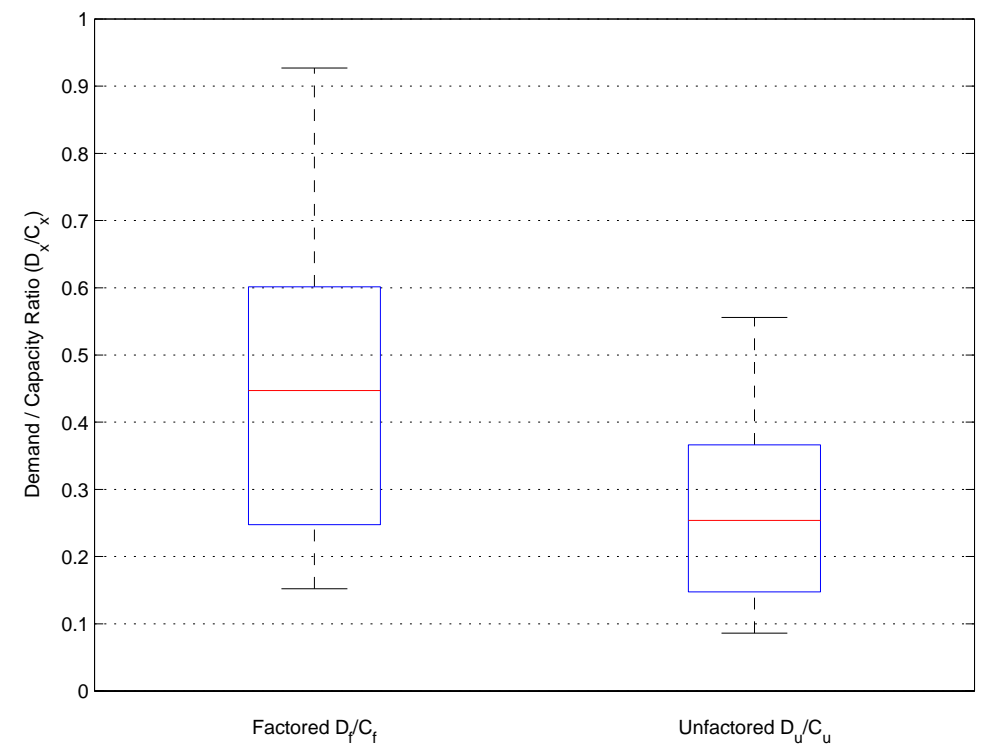

Figure 4: Box plots of factored and unfactored D/C ratios, $D_{f} / C_{f}$ and $D_{u} / C_{u}$. The horizontal black lines mark the maximum and minimum factored or unfactored $D / C$ values; the top and bottom of the blue box mark the $25^{\text {th }}$ and $75^{\text {th }}$ percentile values; the red horizontal line marks the median value. The difference between values of $D_{f} / C_{f}$ and $D_{u} / C_{u}$ is essentially representative of the safety margin provided by load and resistance factors or the safety factor and the difference between $D_{f} / C_{f}$ and 1.0 indicates the margin between optimal structural efficiency and as-built efficiency.

Figure 5 provides $D_{f} / C_{f}$ statistics grouped by the structural system in which the corresponding component participates: the $2^{\text {nd }}$ floor gravity system and the lateral force system on each of the four sides of the building. The variability in building-wide $D_{f} / C_{f}$ shown in Figure 4 is not simply a result of mixing various groups of components, rather within each structural system there is significant variability in $D_{f} / C_{f}$. Furthermore, $D_{f} / C_{f}$ is much smaller, across the board, for the lateral force systems than for the gravity system. This essentially implies reduced efficiency of those systems with respect to the optimal efficiency condition $D_{f} / C_{f}=1.0$. This reduced efficiency, and the variability across shear wall systems of the $D / C$ ratios may be indicative of the relatively limited, and discrete, options available to designers in the prescriptive code for specifying shear walls, particularly with respect to sheathing thickness, fastener type, and spacing. 


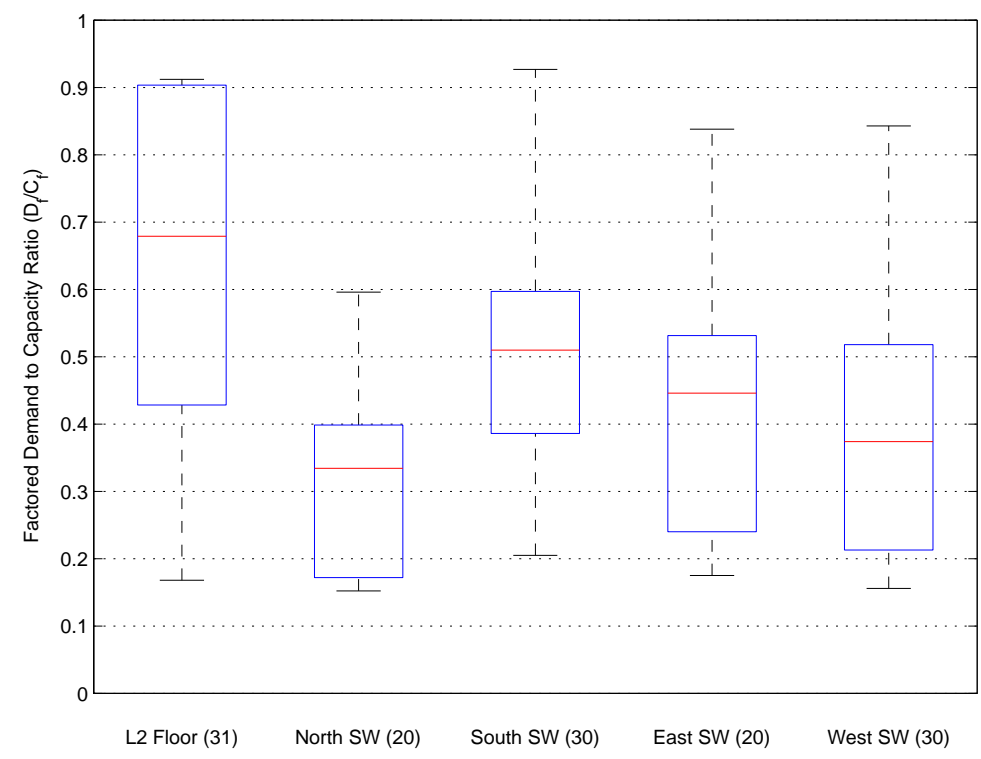

Figure 5: Box plots of $D_{f} / C_{f}$ for building regions (See Figure 4 caption for box plot graphical conventions.) Numbers in parentheses indicate the number of components in each group, and "SW" abbreviates "shear wall system". Five building regions are shown: the gravity load system for the second floor and the lateral force systems for each of the four sides of the building.

Each of the structural systems identified in Figure 5 is composed of a variety of component types, and Figure 6 shows $D_{f} / C_{f}$ for each of these component groups. Joists and headers/carriers are part of the $2^{\text {nd }}$ floor gravity system and all other component groups are part of the lateral force system, the shear walls. Figure 6 shows the implications for material efficiency of using consistent member sizes whenever possible. The range of $D_{f} / C_{f}$ is by far largest for the joist group, in which a single member size has been used across all span lengths and demands, and $D_{f} / C_{f}$ decreases substantially from the level 1 to level 2 for the chords and sheathing because component size is again held constant but lateral demand decreases from the first to second level. It is also interesting to note that for component groups with minimum and maximum values there are significant outliers (joists, level 1 sheathing, level 2 sheathing, hold downs and ties) in four of five cases it is the minimum rather than the maximum that is the outlier. This would seem to be a preferable situation with regard to efficiency than one in which the outlier is more often a maximum of $D_{f} / C_{f}$ since such a case would imply that a single component of the group was driving significant over-design of the remaining members of the group. 


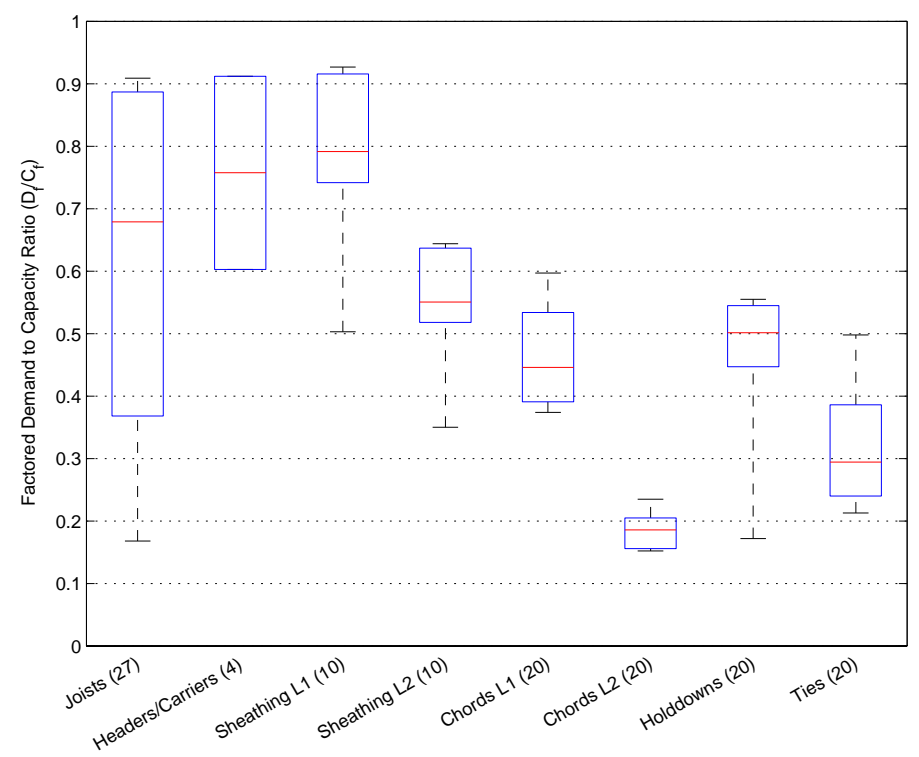

Figure 6: Box plots of $D_{f} / C_{f}$ for building component groups (See Figure 4 caption for box plot graphical conventions.) Numbers in parentheses indicate the number of components in each group. Joists and Headers/Carriers are part of the $2^{\text {nd }}$ floor gravity system and all other component groups are part of the lateral force system.

\section{Component reliabilities}

Component demand and capacity can be translated to component reliability using the procedures and equations (specifically equation 12) of Section 3.2 in which $D / C$ is treated as a lognormal random variable. As-designed component reliabilities for the CFS-NEES building are now presented in a manner parallel to the presentation of $\mathrm{D} / \mathrm{C}$ ratios in the previous section. A key difference in the presentation of $\mathrm{D} / \mathrm{C}$ ratios and component reliabilities $\beta$ is that while the factored ratios $D_{f} / C_{f}$ are emphasized because they provide direct insight into the structural efficiency of the design, the unfactored reliability $\beta_{u}$ is emphasized over $\beta_{f}$ because it reflects the actual probability of failure of the component. The factored reliability $\beta_{f}$ provides information only about the probability that the design check on factored demand and capacity might not be actually satisfied in the as-designed building due to uncertainty in the demand and capacity.

Values of $\beta_{u}$ should be interpreted in comparison to target values implicit in the code, namely $\beta_{0}$ $=3.5$ for ties and hold downs acting as part of the lateral force system shear walls and $\beta_{0}=2.5$ for all other components (AISI S100 section F1.1(c)). Furthermore, values of $\beta_{u}$ correspond to probabilities of failure in a nonlinear fashion that is summarized in Table 2 so that the reader may have an easy reference to failure probabilities. 
Table 2: Relation between reliability index and probability of failure

\begin{tabular}{cc}
$\begin{array}{c}\text { Reliability } \\
\text { index }(\beta)\end{array}$ & $\begin{array}{c}\text { Prob. of Failure } \\
\left(P_{f}\right)\end{array}$ \\
\hline 2.0 & $2.3 \times 10^{-2}$ \\
2.5 & $6.2 \times 10^{-3}$ \\
3.0 & $1.3 \times 10^{-3}$ \\
3.5 & $2.3 \times 10^{-4}$ \\
4.0 & $3.2 \times 10^{-5}$ \\
5.0 & $2.9 \times 10^{-7}$ \\
7.5 & $3.2 \times 10^{-14}$ \\
10 & $7.6 \times 10^{-24}$
\end{tabular}

Similar to the $D / C$ ratios, component reliabilities $\beta_{u}$ are depicted on drawings of the CFS-NEES building

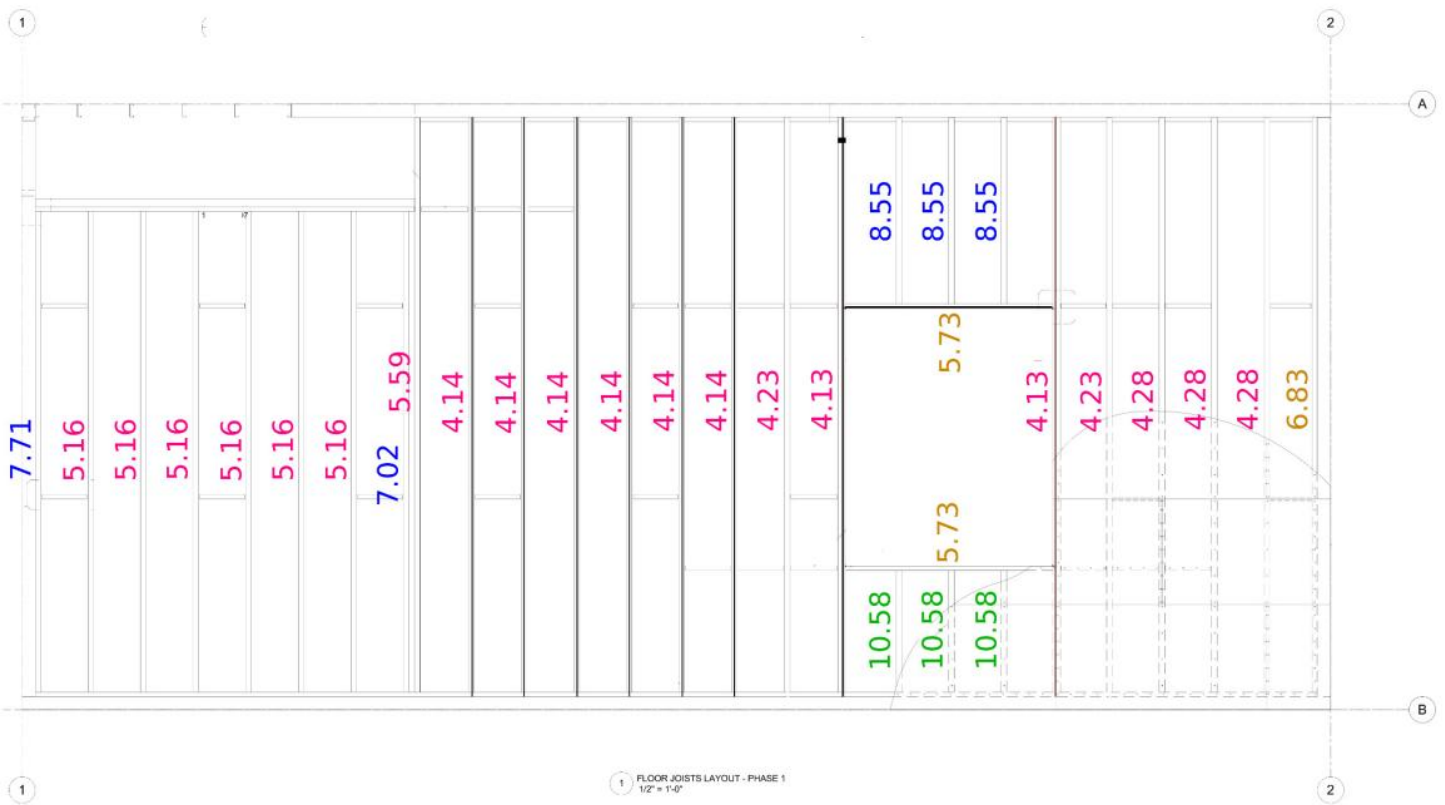

Figure 7 and Figure 8 to indicate the spatial distribution of component reliability within the building. The spatial patterns shown are similar to those for the $D / C$ ratios in Figure 2 and Figure 3 , namely that the lowest reliability in the second floor gravity system occurs adjacent to the framed opening and reliabilities of the lateral force system increase from level 1 to level 2 . Overall, as-designed reliabilities are quite high, with many components having $\beta_{u}>5.0$ (i.e. $\mathrm{P}_{\mathrm{f}}<$ $\left.2.9 \times 10^{7}\right)$. 


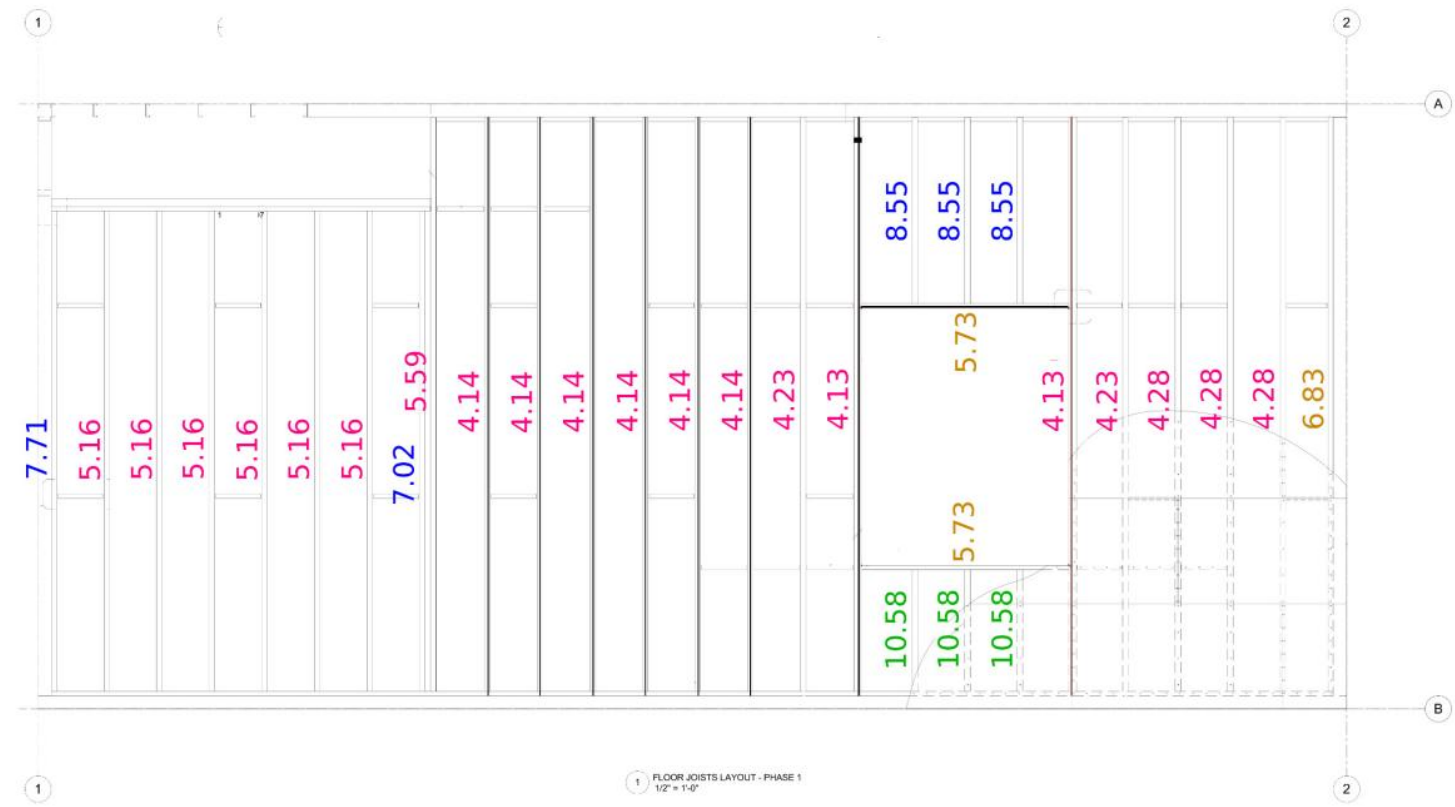

Figure 7: $2^{\text {nd }}$ floor gravity system component unfactored reliabilities $\beta_{u}$. Text colors correspond to the quartile in which the member lies, with pink indicating most severe $25 \%$ of ratios, and orange, blue, and green indicating progressively less severe $\beta_{u}$ quartiles. Note that a member's quartile in this figure may differ from those in the similar $D_{f} / C_{f}$ ratio figure (Figure 2). Members indicated by a bold black line are the critical members which governed design choices. 


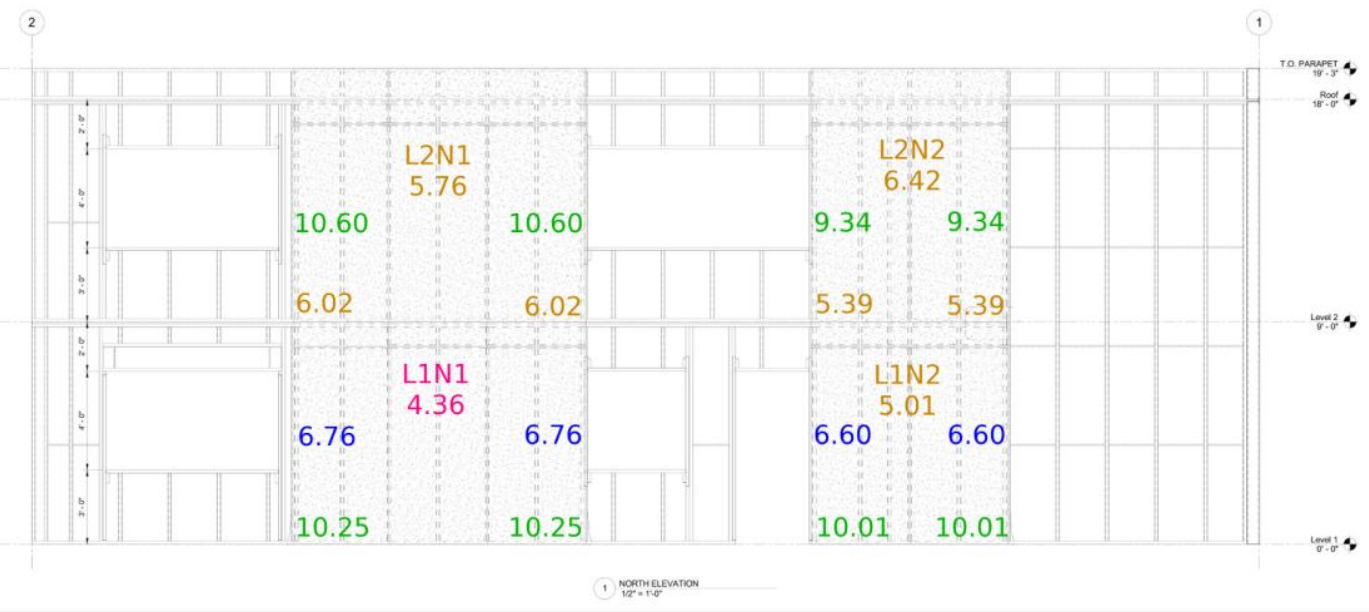

(a) $\beta_{u}$ for north elevation

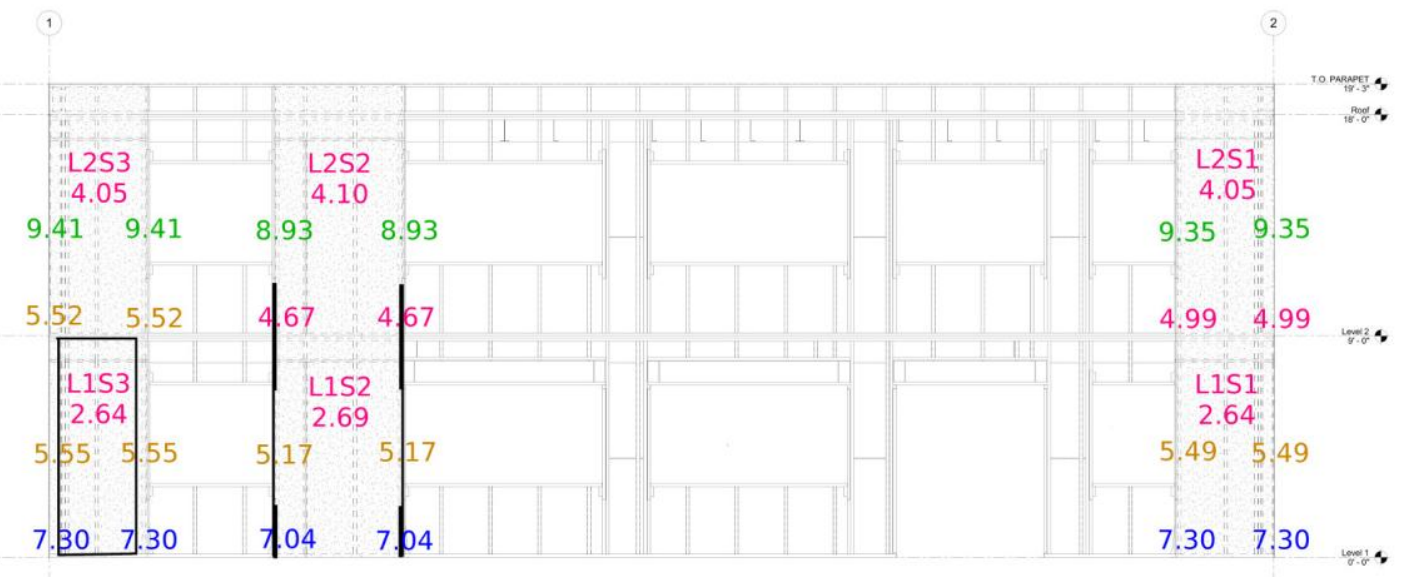

(1) sompreavation

(b) $\beta_{u}$ for south elevation

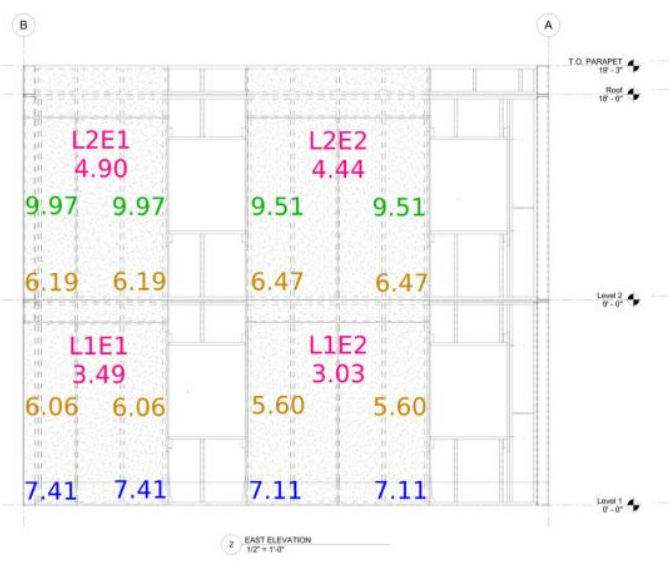

(c) $\beta_{u}$ for east elevation

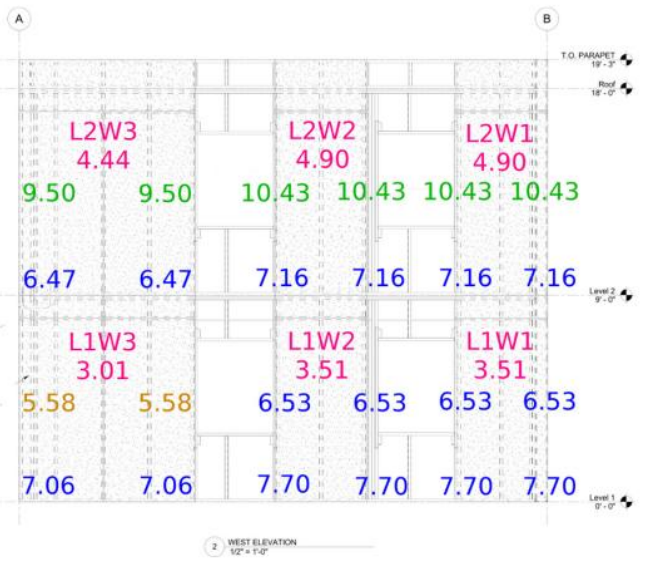

(d) $\beta_{u}$ for west elevation

Figure 8: Shear wall system component unfactored reliabilities $\beta_{u}$. See Figure 7 for graphical conventions. 
Box and whisker plots of $\beta_{u}$ by structural system and component group (Figure 9 and Figure 10) show results that also parallel the box and whisker plots of $D_{f} / C_{f}$, (Figure 5 and Figure 6 ) with the exception that in Figure 10, which shows $\beta_{u}$ by component group, the target reliability for each group is also shown as a horizontal black line. That the line indicating target reliability is always below the minimum as-designed reliability is indicative of the fact that design checks have been passed for all members and the minimum target reliabilities have been met. For all component groups except the L1 sheathing even the component with minimum reliability has reliability significantly in excess of the target reliability. Consultation with Table 2 reveals that the excess reliability translates to decreased probabilities of failure that are often two orders of magnitude or more smaller than the target failure probability.

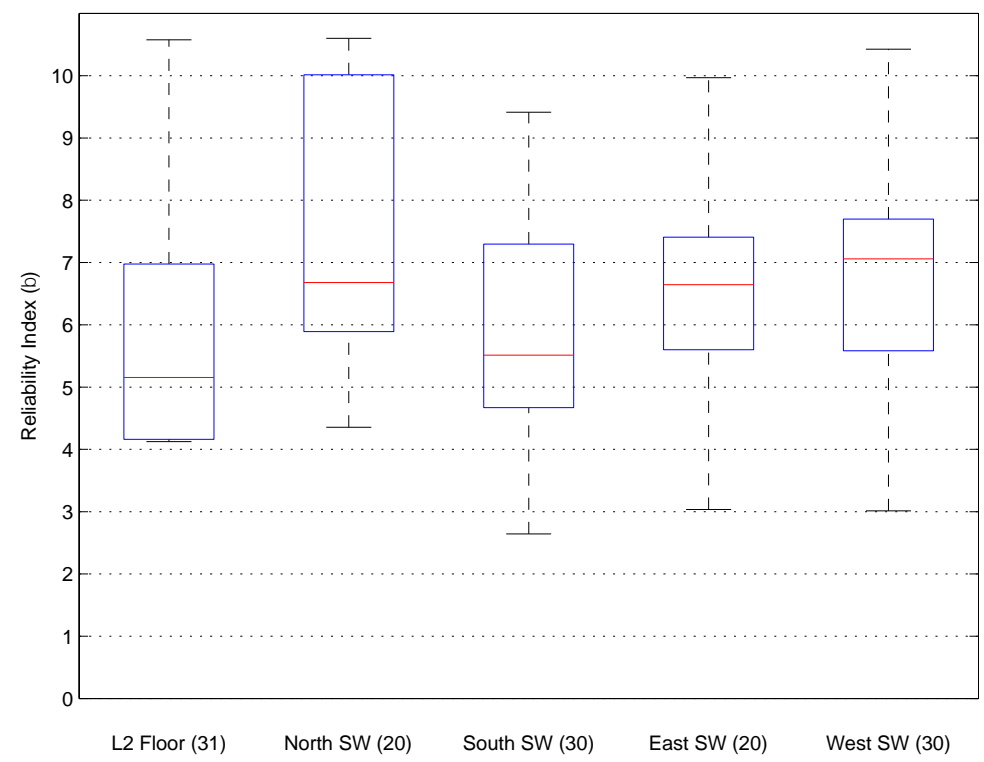

Figure 9: Box plot of component reliabilities $\beta_{u}$ grouped according to structural system. (See Figure 4 caption for box plot graphical conventions.) Numbers in parentheses indicate the number of components in each group. 


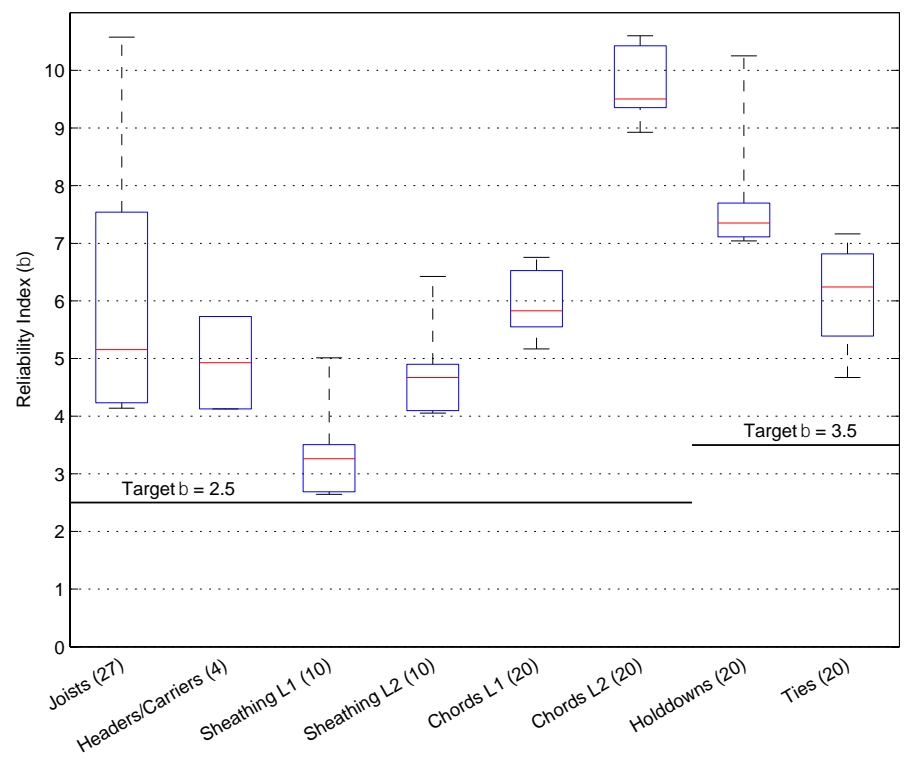

Figure 10: Box plots of $\beta_{u}$ for building component groups (See Figure 4 caption for box plot graphical conventions.) Numbers in parentheses indicate the number of components in each group, and the black horizontal line indicates the implicit target reliability for each group, equal to 3.5 for hold downs and ties and 2.5 for all other component groups. Joists and headers/carriers are part of the $2^{\text {nd }}$ floor gravity system and all other component groups are part of the lateral force system.

\section{Discussion}

Results presented in Sections 4 and 5 indicate that the as-designed CFS-NEES building, with the exception of a few critical components, has components that meet design requirements by large margins and with a great degree of variability. This situation results from tradeoffs in the design process, in which ease of constructability is favored over component-by-component optimization. The implications of this tradeoff for component reliability have not previously been quantified, and the degree to which constructability and design efficiency considerations result in variable and excess component reliability is striking.

For example, in the second floor gravity system, a single critical joist drives member sizing for the entire floor. Should this joist fail (despite having an as-designed reliability over 4.0), the excess reliability and the fact that other members in the flooring system have much higher reliabilities increase the likelihood that an alternate load path will still be available to the loads previously carried by the failed joist. Thus, in systems where some degree of load redistribution is possible, the results presented here indicate that system reliabilities may be significantly higher than anticipated by the prescriptive code, which contains implicit reliabilities only for the components.

The excess component reliabilities and low $D / C$ ratios reported here may seem to indicate a gross lack of structural efficiency in the design of the CFS-NEES building. Rather, they are a natural outgrowth of a design process in which efficiency of construction (consistent member sizes and connection details) and design (fewer and simpler calculations) is at least as important as material efficiency, and in which the designer has access to a finite set of discrete design parameters (joist size, fastener spacing, OSB thickness, etc.). Since these design incentives and constraints are present in all CFS designs, it is likely that the conditions of excess and variable as-designed reliability prevail broadly across CFS structural systems. Since the overarching objective of design is to ensure adequate performance of structural systems, if it could be shown through further research that adequate performance did prevail, it would be appropriate to consider modifying the design codes. Design codes could possibly make allowance, in some way that 
would continue to ensure component reliability, for the added system effects induced by excess and variable component reliability.

Another important consideration that is not reported in the results sections is that different components may be governed by different load combinations. For the gravity system the controlling load case is $1.2 D+1.6 L$ whereas the components of the lateral force system are variously controlled by $1.2 D+1.0 L+0.2 S+1.0 E, 0.9 D+1.0 E$, or $1.0 E$ (ASCE 7-10, Chapter 2). In the load combination notations the symbols $D, L, S$, and $E$ stand for dead, live, snow, and earthquake loads respectively. The load combination $1.0 \mathrm{E}$ is not a typical load combination, but in the AISI specification there is a shear wall system capacity check that evaluates capacity relative to the seismic demand in isolation from all other loads. Furthermore, several components critical to the lateral force resisting system are designed based not upon traditional load combinations but upon a seismic overstrength factor or upon the capacity of the shear wall system itself. In the latter case, the component is designed such that the demand is equal to the maximum forces that other components in the system could possibly impart upon it, regardless of what forces are actually predicted. These high demands are intended to increase the reliability of the component beyond the target reliability. It should be noted that while the above findings are developed for a building in which seismic forces govern lateral system design, there is no reason to believe that distributions and variability of $D / C$ and $\beta$ would differ significantly for a building controlled by wind forces. The gravity system would be similarly designed, and while there is no overstrength factor and design methodology differs with wind loading, members and components of the lateral system interact similarly.

AISI S100 specifies a coefficient of variation ( $V_{Q}$ in section F1.1(c)) of 0.21 for all load combinations, and that value has been used in all calculations presented previously. Meimand and Schafer [23], however, have shown that different load combinations should have different coefficients of variation associated with them. For example, they calculate that the load combination $1.2 D+1.6 L$ should have an associated coefficient of variation of only 0.17 since it consists entirely of gravity loads with well understood properties. On the other hand, they recommend a coefficient of variation of 0.66 for the $1.2 D+1.0 L+0.2 S+1.0 E$ load combination due to the very high uncertainty associated with earthquake loads. Clearly, incorporation of different coefficients of variation for each load combination would have dramatic implications for the resulting as-designed component reliabilities. For example, for the most critical second floor joist, the component reliability would increase from $\beta_{u}=4.1$ to $\beta_{u}=4.7$ if the recommended value of 0.17 is used for the COV of the controlling load case of $1.2 D+1.6 L$. Conversely, for the most critical level 1 shear wall chord the component reliability would drop dramatically, from $\beta_{u}$ $=5.2$ to $\beta_{u}=2.0$, below the target reliability, if the recommended value of 0.66 is used for the $\mathrm{COV}$ of the controlling load combination $1.2 D+1.0 L+0.2 S+1.0 E$. Inclusion of different load combination COVs would thus serve to exacerbate the variability of as-designed reliability that is already present in the CFS-NEES building, and likely is typical of most CFS structures. Large COVs associated with seismic loads mean that components governed by seismic loads may not meet target reliabilities. Although the illustration here is for a CFS building, seismic load factors and COVs are independent of structural system and therefore the effect of seismic load COV on component reliability should be considered typical of all buildings governed even partially by seismic loads.

\section{System reliability}

Although the focus of this paper is on the as-designed $D / C$ ratios and component reliabilities of the CFS-NEES building, the primary goal of structural design is to deliver structural systems with sufficient reliability. In this section, therefore, a simplified system reliability analysis of a portion of the lateral force resisting systems of the CFS-NEES building is presented to illustrate how 
variable and excess reliability propagates from the components to the systems. The selected system resists lateral load applied in the N-S direction, perpendicular to the long axis of the building floorplan. This system consists of the $2^{\text {nd }}$ floor diaphragm, the two shear walls on the east side of the building, and the three shear walls on the west side of the building [15]. The diaphragm action of the $2^{\text {nd }}$ floor is not directly considered in this paper since joists are sized based on gravity demands, but in other work the overall reliability of the diaphragm has been estimated as $\beta_{u}=5.0$ [23], and that value is used here. The shear walls are a subsystem consisting of chord studs, hold downs, ties, and OSB sheathing (fasteners are neglected in this reliability analysis). Table 3 gives the values of $\beta_{u}$ computed in this paper for each of the components of the east and west shear walls, and these component reliabilities, along with the diaphragm reliability, are used in computing the N-S lateral force system reliability.

Also included in Table 3 are the (sub)system reliabilities for each individual shear wall, computed using two sets of assumptions regarding the interaction of shear wall components, and the groups of shear walls along the east and west edges. Calculation of system reliability requires either a high fidelity computational or analytical model with which Monte Carlo simulation or other computational techniques can be performed, or a simplified analytical model that allows propagation of failure probabilities from the component to the system scale. In this study two simplified analytical models are used for shear wall reliability calculation to illustrate the range of subsystem reliabilities that can be predicted using rational engineering models and to illustrate the sensitivity of the overall system reliability to those assumptions. The two models, one that provides a lower bound on shear wall reliability and one that provides a higher estimate of shear wall reliability, are:

1. Series: All shear wall components (chord studs, sheathing, hold downs) act in series such that if any one of those components fails the entire shear wall is assumed to fail. This is a highly conservative assumption that will deliver a lower bound on the shear wall reliability.

2. Hybrid Series/Parallel: Some degree of parallel, or load sharing action, is considered. Specifically, chord studs are assumed to act in parallel with each other and hold downs are assumed to act in parallel with each other. Then, the group of chord studs, the group of hold downs, and the sheathing are assumed to act in series with one another. In this model, shear wall failure can occur when all chord studs fail, when all hold downs fail, or when the sheathing fails. This is a less conservative model that may tend to overpredict shear wall reliability

The reader is reminded at this point that the sheathing component calculation also acts as a surrogate for the shear wall subsystem capacity since the fastener type and spacing and chord dimensions are included in the prescriptive strength prediction from AISI S213. An alternative approach to computing the reliability of a shear wall would be to take the minimum of the sheathing reliability and the series reliability of the remaining components. In this particular example, since the sheathing reliability is much smaller than any of the other component reliabilities, the two approaches produce comparable estimates.

Within a shear wall group (L1E1 + L2E1 + L1E2 + L2E2; L1E1 + L2W1 + L1W2 + L2W2 + L1W3 + L2W3; see Figure 1), the individual walls are assumed to have a parallel-ductile type behavior, such that the shear wall group fails only when all of the constituent shear walls have failed. Key assumptions in this approximation to the subsystem behavior include: (1) no alternate lateral load paths exist through the gravity walls; (2) independence of the behavior/failure of the shear walls within a group; (3) neglect of load redistribution within a shear wall group after assumed ductile failure of a member of that group. In reality, demands on individual shear walls arise from the same source (for example, a seismic ground motion) and are highly correlated, such that assumption 2 (independence) leads to underestimation of the failure probability of a 
shear wall group. Since assumption (3) states that the individual shear walls are fully ductile (they never undergo strength-degradation), increased demands on the surviving shear walls after the first shear wall has failed would lead to higher failure probabilities than predicted. Finally, assumption (1) overestimates the actual failure probability because in reality gravity walls add to system resilience but are completely neglected here. Nevertheless, these assumptions allow simple hand calculations of the system reliabilities and are therefore implemented here to illustrate the relationship between component and system reliability.

Table 3: Unfactored reliabilities $\left(\beta_{u}\right)$ for shear wall components and shear wall subsystem reliabilities assuming series behavior for the components of a shear wall and parallel behavior between the 2 east and 3 west shear walls

\begin{tabular}{|c|c|c|c|c|c|}
\hline Component & East 1 & East 2 & West 1 & West 2 & West 3 \\
\hline Level 1 & & & & & \\
\hline Sheathing & 3.5 & 3.0 & 3.5 & 3.5 & 3.0 \\
\hline Chords & 6.0 & 5.6 & 6.5 & 6.5 & 5.6 \\
\hline $\begin{array}{l}\text { Holddowns } \\
\text { Level } 2\end{array}$ & 7.4 & 7.1 & 7.7 & 7.7 & 7.1 \\
\hline Sheathing & 4.9 & 4.4 & 4.6 & 4.6 & 4.4 \\
\hline Chords & 9.9 & 9.5 & 10 & 10 & 9.5 \\
\hline Ties & 6.8 & 6.5 & 7.1 & 7.1 & 6.5 \\
\hline \multicolumn{6}{|l|}{ Series } \\
\hline Shear wall & 3.5 & 3.0 & 3.5 & 3.5 & 3.0 \\
\hline SW group & \multicolumn{2}{|c|}{5.0} & \multicolumn{3}{|c|}{6.4} \\
\hline \multicolumn{6}{|c|}{ Hybrid Series/Parallel } \\
\hline Shear wall & 6.7 & 6.4 & 7.0 & 7.0 & 6.4 \\
\hline SW group & \multicolumn{2}{|c|}{9.5} & \multicolumn{3}{|c|}{12} \\
\hline
\end{tabular}

From Table 3 it can be observed that the choice of model for shear wall behavior can have a significant effect on the estimate of shear wall reliability. For example, for the East 1 shear wall the reliability is 3.5 based on the series model and 6.7 based on the hybrid series/parallel model. Similar effects are present for the other shear walls and these increased reliabilities propagate dramatically to the shear wall group reliabilities.

Combining the subsystem reliabilities of Table 3 with the diaphragm reliability, and assuming that the diaphragm and shear wall subsystems act in series (which means the probabilities of failure of each subsystem are multiplied together), the total reliability of the N-S lateral force system is 4.9 based on series behavior within shear walls and 5.0 based on hybrid series/parallel behavior within shear walls, both well in excess of typical target values of $2.5-3.5$. Assuming that the diaphragm and shear walls act in series is conservative to some degree, but since full parallel behavior is not realistic (if the entire east side shear wall group fails during a seismic event significant torsion effects would ensue and the west end shear walls would be unlikely to be able to maintain integrity of the building) improvement upon the series assumption would require more sophisticated modeling of the entire structural system. Such modeling is a subject of ongoing work by the authors.

Due to the variable and excess reliability present in the shear wall components, shear wall reliabilities are dominated by the reliability of the least reliable component, in each case the level 1 sheathing. In a system with more uniform reliabilities, on the other hand, the system reliability is much smaller than the minimum component reliability. For example, if each component in the L1E1 and L2E2 shear walls were designed with target reliability (3.5 for the ties and hold downs 
and 2.5 for all others) the resulting subsystem reliability would be only 1.8 based on series behavior and 3.1 based on hybrid series/parallel behavior. Parallel load sharing ability within shear wall groups (which results in the failure probability being the complement of the product of the individual survival probabilities) adds significantly to the system reliability. This is evident in that the east shear wall group achieves a reliability of 5.0 from shear walls with reliabilities of 3.5 and 3.0, and a similar effect is present for the west shear wall group.

For comparison, if one assumes that all shear wall components are designed to the appropriate target reliability and that the diaphragm has a $\beta_{u}=2.5$, the total system reliability for the N-S lateral force system (obtained by multiplying the diaphragm, east shear wall and west shear wall reliabilities) would be $\beta_{u}=2.4$ under series behavior and 2.5 under hybrid series/parallel behavior. The total system reliabilities are relatively insensitive to the choice of model for the shear walls since, in a series system (diaphragm-shear walls in this case) the smallest reliability is critical and raising the reliability of a single component has little effect.

System reliability calculations made using simple assumptions about the interaction of the subsystems of the lateral force system of the CFS-NEES building reveal that the overall system reliability is significantly in excess of the assumed target reliability and that this excess reliability comes directly from excess reliability at the component level that is a natural outgrowth of efficient and customary design procedures. The results of Table 3 illustrate that the shear wall reliabilities are governed by the sheathing/shear wall subsystem check even when all shear wall components are assumed to act in series. This illustrative system reliability calculation is sensitive to assumptions about parallel/series coupling of the subsystems and further investigation of the nature of the coupling of these subsystems (either experimental or computational) is warranted.

\section{Conclusions}

The design of the CFS-NEES building has been analyzed to determine the demand-to-capacity ratios and reliabilities of constituent components of the second floor gravity system and the lateral force resisting system. As part of these calculations, demand and capacity before and after application of load and resistance or safety factors have been computed. Factored demand-tocapacity ratios give insight into the structural efficiency of the design with respect to code prescribed design checks and unfactored component reliabilities define estimates of the probability of failure of the components. Results of this case study show that constructability and design considerations that favor use of uniform member sizes, along with the need to meet serviceability requirements, result in demand-to-capacity ratios that are significantly lower than the most efficient value of 1.0 and that there is tremendous variability within the building of the demand-to-capacity ratios. Similarly, component reliabilities significantly exceed target values and vary substantially within the building. For components with a target of $\beta=2.5$ as-designed $\beta$ ranges from 2.6 to over 10 and for components with a target of $\beta=3.5$ as designed $\beta$ ranges from 4.7 to 7.2. Excess reliability and variability of reliability has implications for system reliability and this effect is investigated through a simplified series-parallel model for the lateral force resisting system of the building. This analysis shows that the system reliability is well in excess of the reliability of the least reliable member, largely due to the large excess reliability present in many of the components. As designers and code-writing committees seek to incorporate system reliability effects into their procedures suites of other typical designs should be evaluated for the excess and variable as-designed reliability documented here for the CFS-NEES building. Specifically, it would be productive to collect and analyze designs of actual commercial and residential buildings of different sizes and heights and in different regions of the USA. Such a collective analysis would allow stronger conclusions to be drawn regarding component and system reliability effects than are permitted by this case study of a single building. If component reliability is found to be distributed similarly in other typical designs, opportunities may exist to account for this feature of the as-designed component reliabilities in design codes. 


\section{Acknowledgments}

The financial and in-kind support of the American Iron and Steel Institute is gratefully acknowledged, as is the financial support provided by the United States National Science Foundation through grants CMMI-1301033, 1301001, and 1300484. Any opinions, findings, and conclusions or recommendations expressed in this material are those of the authors and do not necessarily reflect the views of the American Iron and Steel Institute or the National Science Foundation.

\section{References}

[1] Serrette R, Encalada J, Juadines M, Nguyen H. "Static Racking Behavior of Plywood, OSB, Gypsum, and FiberBoard Walls with Metal Framing," Journal of Structural Engineering 1997; 123(8): 1079-1086.

[2] Landolfo R, Fiorino L, Della Corte G. "Seismic Behavior of Sheathed Cold-Formed Structures: Physical Tests," Journal of Structural Engineering 2006; 132(4): 570-581.

[3] Fiorino L, Della Corte G, Landolfo R. "Experimental tests on typical screw connections for cold-formed steel housing," Engineering Structures 2007; 29(8): 1761-1773.

[4] Iuorio O, Fiorino L, Landolfo R. "Testing CFS Structures: The New School BFS in Naples," Thin-Walled Structures 2014; 84: 275-288.

[5] Fülöp LA, Dubina D. "Performance of Wall-Stud Cold-Formed Shear Panels Under Monotonic and Cyclic Loading - Part II: Numerical Modelling and Performance Analysis," ThinWalled Structures 2004; 42(2): 339-349.

[6] Dubina D. "Behavior and Performance of Cold-Formed Steel-Framed Houses Under Seismic Action," Journal of Constructional Steel Research 2008; 64(7-8): 896-913.

[7] Gad EF, Duffield CF, Hutchinson GL, Mansell DS, Stark G. "Lateral Performance of ColdFormed Steel-Framed Domestic Structures," Engineering Structures 1999; 21(1): 83-95.

[8] Li Y, Shen S, Yao X, Ma R, Liu F. "Experimental Investigation and Design Method Research on Low-Rise Cold-Formed Thin-Walled Steel Framing Buildings," Journal of Structural Engineering 2012; 818-836. doi:10.1061/(ASCE)ST.1943-541X.0000720.

[9] Moses F. "System Reliability Developments in Structural Engineering," Structural Safety 1982; 1: 3-13.

[10] Rashedi R, Moses F. "Identification of Failure Modes in System Reliability," Journal of Structural Engineering 1988; 114(2): 292-313.

[11] Ellingwood BR, Kinali K. "Quantifying and communicating uncertainty in seismic risk assessment," Structural Safety 2009; 31: 179-187.

[12] Hendawi S, Frangopol DM. "System reliability and redundancy in structural design and evaluation," Structural Safety 1994; 16: 47-71.

[13] Schafer BW. Website for "NEESR-CR: Enabling Performance-Based Seismic Design of Multi-Story Cold-Formed Steel Structures," www.ce.jhu.edu/cfsnees, accessed on 12 May 2015.

[14] Peterman K, Schafer BW, Madsen RL, Buonopane S, Nakata N. "Experimental Performance of Full-Scale Cold-Formed Steel Buildings Under Seismic Excitations," Network for Earthquake Engineering Simulation (NEES) (distributor), 2014, Dataset, DOI: 10.4231/D3DB7VR05.

[15] Peterman K. "Behavior of Full-Scale Cold Formed Steel Buildings Under Seismic Excitations," Ph.D. Dissertation 2014, Johns Hopkins University. 
[16] Nakata N, Schafer BW, Madsen RL. "Seismic Design of Multi-Story Cold-Formed Steel Buildings: the CFS-NEES Archetype Building," 2012 Structures Congress, March 2012, Chicago, Illinois. p.1507-1517.

[17] Madsen RL, Nakata N, Schafer BW. "CFS-NEES Building Structural Design Narrative", Research Report, RR01, www.ce.jhu.edu/cfsness, Accessed October 2011, revised RR01b April 2012, revised RR01c May 2012.

[18] American Society of Civil Engineers. "Minimum Design Loads for Buildings and Other Structures,” ASCE Standard ASCE/SEI 7-05, 2006.

[19] American Iron and Steel Institute. "North American Standard for Cold-Formed Steel Framing - Lateral Design,” AISI Standard AISI S213-07, 2007.

[20] American Iron and Steel Institute. "North American Specification for the Design of ColdFormed Steel Structural Members," AISI Standard AISI S100-07, 2007.

[21] American Society of Civil Engineers. "Minimum Design Loads for Buildings and Other Structures," ASCE Standard ASCE/SEI 7-10, 2011.

[22] American Iron and Steel Institute. "North American Specification for the Design of ColdFormed Steel Structural Members," AISI Standard AISI S100-12, 2012.

[23] Meimand VZ, Schafer BW. "Impact of Load Combinations on Structural Reliability Determined from Testing Cold-Formed Steel Components," Structural Safety 2014; 48: 25-32.

[24] Chatterjee A, Xiang Y, Moen CD, Arwade SR, Schafer BW. "Towards Quantifying Benficial System Effects in Cold Formed Steel Wood-Sheathed Floor Diaphragms, 2nd International Specialty Conference on Cold-Formed Steel Structures, November 2014, St Louis, Missouri.

[25] Schafer BW. "Review: The Direct Strength Method of cold-formed steel member design." Journal of Constructional Steel Research 2008; 64(7/8):766-778. 